

\title{
(Des) legitimação da informação contábil em processos licitatórios no Brasil
}

(De) legitimization of accounting information in public procurement processes in Brazil

\section{(Des) legitimación de la información contable en los procesos de contratación pública en Brasil}

\author{
Rafael Borges Ribeiro \\ Doutor em Ciências Contábeis (UFU) \\ Professor Adjunto na Faculdade de Ciências Contábeis \\ FACIC (UFU), Uberlândia/MG, Brasil \\ rafael@ufu.br \\ https://orcid.org/0000-0002-3762-498X
}

\author{
Gilberto José Miranda \\ Doutor em Controladoria e Contabilidade da FEA (USP) \\ Professor Associado na Faculdade de Ciências Contábeis \\ FACIC (UFU), Uberlândia/MG, Brasil \\ gilbertojm@ufu.br \\ http://orcid.org/0000-0002-1543-611X \\ Ricardo Rocha de Azevedo \\ Doutor em Controladoria e Contabilidade da FEARP (USP) \\ Professor Adjunto na Faculdade de Ciências Contábeis \\ FACIC (UFU), Uberlândia/MG, Brasil \\ ricardo.azevedo@ufu.br \\ https://orcid.org/0000-0001-6302-0760 (1)
}

Endereço do contato principal para correspondência* Av. João Naves de Ávila, 2121 - Bloco F - Sala 1F 249, Campus Santa Mônica, CEP: 38.400-902 - Uberlândia/MG, Brasil

\section{Resumo}

O objetivo deste estudo consiste em analisar a legitimidade da informação contábil na etapa de qualificação econômico-financeira (QEF) das licitações públicas que envolvem obras de construção civil e serviços de mão de obra terceirizada. Para a interpretação do fenômeno se utilizou dos atributos da legitimidade normativa (normativity) e das características qualitativas da informação contábil presentes na Estrutura Conceitual da contabilidade. Os resultados baseiam-se em análise documental de processos licitatórios de seis instituições federais de ensino superior, complementado por entrevistas com agentes que atuam no processo de QEF. Os resultados indicam que a informação contábil tem sido vista com baixa legitimidade, o que têm prejudicado a avaliação econômica das empresas no processo licitatório. No aspecto teórico, a pesquisa contribui sugerindo que a baixa legitimidade da informação contábil perfaz em fator relevante para seu uso cerimonial, o que pode ser útil para pesquisas e para a prática.

Palavras-chave: Informação Contábil; Legitimidade Normativa; Qualificação Econômico-Financeira; Licitações Públicas

\begin{abstract}
This study consists of analyzing the legitimacy of accounting information in the economic and financial qualification (EFQ) stage of public procurement involving construction industry works, as well as the outsourced laborforce service delivery. For the interpretation of the phenomenon it was used the attributes of normative legitimacy (normativity) and the qualitative characteristics of useful financial information present in the accounting conceptual framework. The results are based on documentary analysis of public procurement processes concerning of six federal higher education institutions, complemented by interviews with agents who work in the EFQ process. This study's finding indicates that the accounting information has been viewed with low level of legitimacy, which has hampered the economic evaluation of companies in the public procurement process. Furthermore, the research contributes by suggesting that the low level legitimacy of accounting information is a relevant factor for its formality use, which can be useful for research and for practice.
\end{abstract}

Keywords: Accounting Information; Normative Legitimacy; Economic and Financial Qualification; Public Procurement 


\section{Resumen}

El objetivo de este estudio es analizar la legitimidad de la información contable en la etapa de calificación económico-financiera (QEF) de licitaciones públicas que involucran obras de construcción civil y servicios de mano de obra tercerizada. Para la interpretación del fenómeno se utilizaron los atributos de legitimidad normativa (normatividad) y las características cualitativas de la información contable presentes en la Estructura Conceptual de la contabilidad. Los resultados se basan en el análisis documental de los procesos de licitación de seis instituciones federales de educación superior, complementados con entrevistas a agentes que trabajan en el proceso QEF. Los resultados indican que la información contable se ha visto con poca legitimidad, lo que ha dificultado la evaluación económica de las empresas en el proceso de licitación. En el aspecto teórico, la investigación contribuye al sugerir que la baja legitimidad de la información contable es un factor relevante para su uso ceremonial, que puede ser útil para la investigación y para la práctica.

Keywords: Información contable. Legitimidad normativa; Calificación económica y financiera. Licitaciones públicas

\section{Introdução}

Um dos temas mais discutidos no âmbito da gestão pública dos países são as contratações públicas, em função da representatividade de volume financeiro dispendido pelos governos, média de $12,5 \%$ do Produto Interno Bruto (PIB), e também pelo fato dos países poderem integrar às contratações públicas, a agenda de questões ambientais e sociais (OECD, 2019). As aquisições públicas, na maioria dos países, principalmente na Europa, estão no topo da agenda de acadêmicos e profissionais que lidam com a administração pública (Milosavljević \& Milanović, 2019).

Sob as diretrizes da New Public Management (NPM), com o enfoque na abordagem do setor público baseada em elementos de eficiência e eficácia, a contratualização entre a administração pública com o setor privado e com o terceiro setor aumentou, o que a tem transformado cada vez mais em uma gestora de contratos por meio da terceirização ou de outras modalidades de contratação (Broadbent \& Guthrie, 2008).

Nesse contexto, novos problemas surgiram, como as situações de empresas que não entregam os serviços, materiais e obras, as quais foram contratadas pelo Estado, além de muitas delas com dificuldades financeiras que poderiam ser verificadas por meio de uma avaliação mais criteriosa dos contratados (Romzek \& Johnston, 2002). Atualmente, esse cenário não mudou, pois a partir do ano de 2016 o número de empresas que têm sido punidas por inadimplência, por inidoneidade e por descumprimento de cláusulas contratuais diversas cresceu em média 200\% ao ano (Transparência Brasil, 2020).

Com o objetivo de assegurar o cumprimento dos contratos, a avaliação da capacidade financeira das empresas é determinada pela etapa de Qualificação Econômico-Financeira (QEF), que envolve exigências intrínsecas à contabilidade, tais como, a apresentação de demonstrações contábeis e os valores mínimos de indicadores econômico-financeiros (Brasil, 1993). Contudo, há indícios, em todo o país, de que essa etapa não está sendo eficaz para avaliar a capacidade econômica e financeira das empresas, pois há casos relevantes de contratos que foram descontinuados por fatores que envolvem a incapacidade financeira das empresas na execução do objeto contratual, tais como os casos apresentados no levantamento realizado pelo Tribunal de Contas da União (TCU). Havia, no ano de 2019, mais de uma centena de obras de grande porte (com valores superiores a $\mathrm{R} \$ 1,5$ milhão) paralisadas em todo o país, causando prejuízos relevantes à sociedade (TCU, 2019).

A Associação dos Membros dos Tribunais de Contas (Atricon, 2019) também realizou um estudo relacionado às obras paralisadas no país. Foram constatadas 2.555 obras com valor superior a $\mathrm{R} \$ 1,5$ milhões, paralisadas no Brasil, sendo que $9,1 \%$ do total foram paralisadas em função de abandonos pelas empresas contratadas.

Em geral as pesquisas realizadas sobre a etapa de QEF buscaram avaliar se os índices econômicofinanceiros exigidos mantinham relação com o objeto contratual, se havia coerência de exigências entre os editais de uma mesma instituição e se técnicas estatísticas poderiam melhorar o processo (Machado, 2006; Sobreira et al., 2014). Não foram encontradas pesquisas que aprofundassem a análise do processo de execução da QEF pelas instituições, ou suas relações com a literatura contábil.

Essa lacuna sugere que a informação contábil pode não estar cumprindo de forma satisfatória as suas finalidades no contexto de contratações públicas (Ribeiro et al., 2020). Nessas circunstâncias podem estar ocorrendo problemas relativos à legitimidade normativa (normativity). A legitimidade normativa ocorre quando os atributos das normas são voluntariamente aceitos por seus usuários, mesmo com ausência de coerção (Franck, 1990). Nesse sentido, questiona-se se questões ligadas à legitimidade da norma na etapa de QEF, tal como o uso de informações contábeis não confiáveis e pouco úteis nos processos, estão contribuindo para descontinuidade de contratos das empresas.

Diante do exposto, o objetivo deste estudo consiste em analisar a legitimidade da informação contábil na Etapa de QEF dos processos licitatórios de Instituições Federais de Ensino. Essa análise se justifica, pois, caso a exigência de informações contábeis presentes na etapa de QEF dos processos 
licitatórios não seja vista pelos atores com legitimidade suficiente para avaliar as situações econômica e financeira das empresas, essa etapa pode estar sendo realizada apenas para demonstrar conformidade à legislação, sem que tenha efetividade.

O estudo utiliza os fundamentos da Teoria da Legitimidade para construir o arcabouço teórico necessário para examinar e explicar a investigação, pois, segundo Bebbington et. al (2012), a legitimidade não depende apenas da autoridade da norma, mas também de suas características internas e dos processos a partir dos quais elas são formadas. Os relatos empíricos da Teoria da Legitimidade aplicados à Contabilidade concentram-se em estudos exploratórios aplicados às organizações, visto que poucos estudos focaram a legitimidade normativa da informação contábil (Deephouse \& Suchman, 2008).

À medida que se tenha um modelo capaz de identificar com maior clareza a realidade econômica das empresas, a administração pública poderá selecionar, de fato, propostas mais vantajosas com base em informações mais fidedignas. Essa possível constatação poderá contribuir, diretamente, para a eficiência na aplicação de recursos e, indiretamente, para a qualidade do gasto público.

Este artigo está estruturado em cinco tópicos. Na introdução apresenta-se o objetivo do estudo, a contribuição esperada e a justificativa da pesquisa. O segundo tópico analisa a etapa de qualificação econômico-financeira relacionando-a com a legitimidade normativa e com as características qualitativas da informação contábil. $O$ terceiro tópico apresenta os métodos utilizados e as respectivas etapas da pesquisa e as informações dos casos analisados. O quarto tópico apresenta as análises documentais dos casos e também a análise segundo a Qualitative Comparative Analyze (QCA). No tópico cinco são apresentadas as considerações finais. E por fim são apresentadas as referências.

\section{Referencial Teórico}

\subsection{Qualificação Econômico-Financeira nas Licitações}

A Constituição Federal de 1988 (Brasil, 1988) determina que as empresas sejam avaliadas em termos econômicos com o objetivo de verificar a capacidade das mesmas de cumprir com o objeto contratual pretendido. Nesse ambiente normativo, a etapa de QEF determina exigências, tais como índices econômico-financeiros e demonstrações contábeis para a avaliação da capacidade econômica e financeira das empresas que devem ser cumpridas nos processos licitatórios.

As exigências da legislação para análise da QEF, elencadas na Tabela 1, não estão sintonizadas com a literatura contábil. Destaca-se a vedação da cobrança de valores mínimos de faturamento, bem como de índices de rentabilidade ou lucratividade (Item 2). Este dispositivo da lei de licitações parece conflitar com a Constituição Federal em sua forma conceitual, pois a própria Constituição permite que seja realizada a qualificação econômica com exigências indispensáveis à garantia de cumprimento do objeto (Brasil, 1988). Além disso, os critérios de valores mínimos de faturamento, índices de rentabilidade ou lucratividade são métricas relacionadas à avaliação econômica das empresas. Portanto, nota-se uma incongruência entre o texto constitucional e a lei de licitações.

Tabela 1:

Itens da legislação que tratam da análise econômico-financeira nas contratações versus literatura

\begin{tabular}{|c|c|c|}
\hline Item & Texto da legislação & Literatura \\
\hline 1 & $\begin{array}{l}\text { Art. } 31, \text { I - Lei } 8.666 / 93 \text { - A documentação relativa à qualificação } \\
\text { econômico-financeira limitar-se-á a: - balanço patrimonial e } \\
\text { demonstrações contábeis do último exercício social[...] }\end{array}$ & $\begin{array}{l}\text { Para análise de tendências, pelo menos } \\
\text { demonstrações contábeis de três exercícios } \\
\text { financeiros (Martins et. al., 2020). }\end{array}$ \\
\hline 2 & $\begin{array}{l}\text { Art. } 31, \S 10 \text { - Lei } 8.666 / 93 \text { - A exigência de índices limitar-se-á à } \\
\text { demonstração da capacidade financeira do licitante [...] vedada a } \\
\text { exigência de valores mínimos de faturamento anterior, índices de } \\
\text { rentabilidade ou lucratividade. }\end{array}$ & $\begin{array}{l}\text { Um dos construtos mais evidentes para os modelos } \\
\text { de previsão de insolvência relaciona-se à } \\
\text { rentabilidade (Pereira \& Martins, 2015; Kanitz, } \\
\text { 1978) }\end{array}$ \\
\hline 3 & $\begin{array}{l}\text { Art. } 31 \text {, § } 20 \text { - Lei } 8.666 / 93 \text { - A Administração, nas compras para entrega } \\
\text { futura e na execução de obras e serviços, poderá estabelecer, no } \\
\text { instrumento convocatório da licitação, a exigência de capital mínimo ou } \\
\text { de patrimônio líquido mínimo. }\end{array}$ & $\begin{array}{l}\text { As análises têm que ser realizadas com base em } \\
\text { informações completas. Representação Fidedigna }\end{array}$ \\
\hline 4 & $\begin{array}{l}\text { Art. } 31, \S 40 \text {, Lei } 8.666 / 93 \text { - Poderá ser exigida, ainda, a relação dos } \\
\text { compromissos assumidos pelo licitante que importem diminuição da } \\
\text { capacidade operativa ou absorção de disponibilidade financeira [...] }\end{array}$ & \\
\hline 5 & $\begin{array}{l}\text { Art. } 19, \text { XIV, IN 06/2013, a) balanço patrimonial e demonstrações } \\
\text { contábeis referentes ao último exercício social, comprovando índices de } \\
\text { Liquidez Geral - LG, Liquidez Corrente - LC, e Solvência Geral - SG } \\
\text { superiores a } 1 \text { (um); }\end{array}$ & $\begin{array}{l}\text { Observar as particularidades setoriais para } \\
\text { definição de índices (Martins et., 2020). }\end{array}$ \\
\hline 6 & $\begin{array}{l}\text { Art. } 19, \text { XIV, IN 06/2013 - b) Capital Circulante Líquido ou Capital de } \\
\text { Giro (Ativo Circulante - Passivo Circulante) de, no mínimo, 16,66\% do } \\
\text { valor estimado da contratação[...] }\end{array}$ & $\begin{array}{l}\text { Não há previsão na literatura para esses } \\
\text { percentuais. }\end{array}$ \\
\hline
\end{tabular}

Fonte: Elaborada pelos autores.

Os estudos de previsão de insolvência evidenciam que a rentabilidade é um construto imprescindível nos modelos testados empiricamente, tanto no Brasil quanto em outros países (Du Jardin, 2015; Pereira \& Martins, 2015). Kanitz (1978, p. 2) destaca que "os primeiros sintomas de uma insolvência 
surgem muito antes que ela se concretize", apontando essa constatação para a importância do uso de indicadores de rentabilidade.

Os índices econômico-financeiros e seus respectivos valores a serem exigidos em editais são: liquidez corrente (LC) e liquidez geral (LG) maiores que 1 (um) e Solvência Geral (SG) menor que 1(um) (Brasil, 2017). Além de esses indicadores exigidos não serem suficientes para uma avaliação mais ampla e criteriosa da empresa, a legislação não considera os parâmetros setoriais, sendo esse um fato que distorce as análises, visto que cada setor empresarial possui particularidades inerentes às suas atividades (Martins et. al., 2020).

Nota-se, portanto, que o ordenamento jurídico não permite que se analise, na essência, a situação econômico-financeira das empresas participantes dos processos licitatórios. As análises se pautam, quase exclusivamente, na forma, que expressa a lei. Com o propósito de melhor compreender esta realidade, alguns estudos têm sido realizados.

Rodrigues et al. (2017) buscaram identificar quais os critérios relativos à liquidez estão sendo exigidos em editais de licitação no Brasil, comparando-os com os parâmetros setoriais. Como resultados, foi observado que os índices exigidos não retratam a realidade dos setores, sugerindo a necessidade de maior alinhamento entre os critérios utilizados pelos licitantes e a realidade do mercado. Em âmbito estadual, Lester et al. (2009) observaram que não há congruência entre os critérios adotados pelo governo nos editais de licitação. Tratando-se de governos locais, destaca-se os estudos de Michelin et al. (2012) em que foi observado que há falta de utilização de índices tradicionalmente utilizados na literatura contábil, tendo esses estudos sugerido a inclusão de outros índices.

Outros estudos tiveram abordagens diferentes das anteriores, tendo alguns deles focado na execução da etapa de QEF, como Sobreira et al. (2014). Os autores observaram que há maior poder de predição com a aplicação do modelo de previsão de falência com a utilização de outros índices contábeis, além daqueles determinados pela legislação (LC, LG e SG). Por seu turno, Carneiro Júnior et al. (2015) constataram que, ao incluírem outros indicadores nas análises, obtiveram maior nível de assertividade e concluíram que uma análise mais robusta poderia selecionar melhor as empresas.

Portanto, nota-se que os estudos relacionados com a etapa QEF focam em dois aspectos principais: (i) existência de problemas de execução dos contratos relacionados a questões financeiras das empresas contratadas; (ii) discrepância entre as determinações da legislação e a literatura para análise da situação econômica e financeira das empresas. Apesar de esses estudos despertarem para a importância do tema, nota-se que os mesmos não analisam a relevância atribuída às informações contábeis utilizadas nos processos licitatórios (CPC 00, 2019).

\subsection{Legitimidade normativa}

As normas ou regras estão em toda parte, seja no grau de moralidade e nas crenças das pessoas e dos grupos, bem como nas organizações e nos sistemas sociais, representadas por diversos instrumentos, tais como: um ato, um procedimento, uma rotina, uma posição, um grupo ou uma equipe, a estrutura ou o status de um grupo, uma estrutura de autoridade, os símbolos organizacionais, dentre outros (Parsons, 1956). Desse modo, o cerne da legitimidade encontra-se na congruência entre essas normas, estruturas e valores socialmente construídos e seus usuários (Deephouse \& Suchman, 2008).

A legitimidade normativa pode ser compreendida como um estado ou condição que reflete concordância voluntária, alinhamento cultural, apoio ou consonância por parte de seus usuários em relação à norma ou à regra, fundamentando-se, majoritariamente, em seus atributos e não em sua autoridade coercitiva (Franck, 1990). Em relação a esse ambiente dinâmico da legitimidade, Salancik e Pfeffer (1978) afirmam que a mesma (legitimidade) é mais notada quando está ausente do que quando está presente, podendo variar em grau ou intensidade de acordo com o nível de concordância de seus usuários com a norma e se apresentar nas seguintes situações: (i) as regras que comumente são obedecidas; (ii) as regras que nunca são obedecidas; e (iii) as regras que são obedecidas com menor frequência (Franck, 1990; Ashforth \& Gibbs, 1990).

Do ponto de vista das propriedades ou atributos que conferem legitimidade às normas, Franck (1990) cita quatro principais: (i) determinação; (ii) validação simbólica; (iii) coerência; (iv) adesão. A determinação consiste na dimensão linguística da norma e está ligada à ideia de clareza textual e interpretação, evidenciando como o poder comunicativo da regra exerce seu próprio impulso em direção à conformidade, como, por exemplo, qual conduta é permitida e qual conduta está fora dos limites (Franck, 1990). O atributo da norma deve ser mais importante do que sua autoridade impositiva e, portanto, os usuários obedeceriam às regras porque eles percebem que a mesma e seus reflexos institucionais têm um alto grau de legitimidade (Franck, 1990).

A adesão consiste na aceitação sistêmica da norma por seus usuários, pois a atração e a conformidade da comunidade são condições indispensáveis para se alcançar a legitimidade, pois essa consiste no padrão pelo qual a comunidade mede a capacidade das regras de serem aplicadas. Franck (1990) sugere estratégias para validar normas simbolicamente, tornar seus objetivos mais claros, obter autoridade para a regra por meio da conexão com outras regras e princípios aceitos e adicionar 
conformidade da regra com uma hierarquia de regras.

Em resumo, não basta a edição de uma lei ou norma para que ela seja seguida, mas, ainda, ela precisa parecer legítima para os atores que irão utilizá-la. Uma das formas é a validação realizada por stakeholders que têm mandato para realizar essa ação. Essa validação pode ser realizada por sistemas de acreditação, como a criação de símbolos ou certificados. Ainda, ela precisa ser compreendida e ser coerente com as demais normas em vigor, de forma a não ter sua legitimidade questionada.

Diversas pesquisas em âmbito internacional têm procurado relacionar contabilidade e legitimidade, tais como os estudos de Hyndman et al. (2018), Liguori et al., (2018) e Aquino et al. (2020). Nesta última, os autores observaram que embora os órgãos de auditoria tenham negligenciado a exigência de conformidade com as IPSAS, os "legisladores" colaboraram entre si para criar normatividade para as normas de contabilidade, pois o processo de normatização no campo da Contabilidade resulta da pressão de diferentes atores do cenário regulatório (Bebbington et al., 2012).

\subsection{Características qualitativas da informação contábil}

Considerando que o fenômeno em análise envolve informações contábeis de empresas privadas que venceram licitações no âmbito público, as características qualitativas da informação contábil foram baseadas nos pronunciamentos do CPC 00 R2 (2019). Destaca-se que as características qualitativas da informação contábil aplicadas ao setor público (CFC, 2016) mantém alinhamento conceitual com o CPC 00 (2019).

Martins et al. (2020) afirmam que a informação financeira é relevante quando é capaz de influenciar as decisões tomadas por seus usuários, ajudando-os a avaliar o impacto de eventos passados, presentes ou futuros. Além disso, para legitimar a importância da informação contábil, é necessário que essa seja fidedigna, atendendo a três atributos: ser completa, neutra e isenta de erros. A utilidade da informação contábil também está atrelada a quatro atributos de melhoria: Comparabilidade, Capacidade de Verificação, Tempestividade e Compreensibilidade (CPC 00, 2019). A Comparabilidade permite que os usuários identifiquem e compreendam similaridades dos itens e diferenças entre eles, comparando-se, no mínimo, dois itens (CPC 00, 2019). Para que a informação seja comparável, coisas similares precisam parecer similares e coisas diferentes precisam parecer diferentes (CPC 00, 2019).

Por sua vez, a Capacidade de Verificação consiste em uma característica que contribui para a representação da realidade econômica da empresa de forma fidedigna, significando que diferentes observadores, conscientes e independentes, podem chegar a um acordo quanto ao retrato de uma realidade econômica em particular para satisfazer a concepção de uma representação autêntica (CPC 00 , 2019). A Tempestividade relaciona-se com a disponibilidade da informação para tomadores de decisão a tempo de poder influenciá-los em suas decisões, sendo, em geral, a informação mais antiga a que tem menos utilidade (CPC 00, 2019). Do contrário, se houver atraso na divulgação da informação, existe possibilidade de impactar a relevância ou a utilidade da mesma. Em se tratando da Compreensibilidade, as demonstrações contábeis são elaboradas para usuários que têm compreensão satisfatória de negócios e de atividades econômicas, bem como que revisem e analisem a informação com acurácia em função de que existem fenômenos que são complexos e não podem ser facilmente entendidos (CPC 00, 2019).

Portanto, as características qualitativas da informação contábil fornecem subsídios e fundamentam a elaboração das demonstrações contábeis com o objetivo de serem úteis na tomada de decisões econômicas e avaliações por parte dos usuários em geral. Informações sobre a natureza e os montantes de recursos econômicos e reivindicações da entidade podem auxiliar usuários a identificarem a fraqueza e o vigor financeiro da entidade que reporta a informação.

Pode-se concluir que os atributos acima apresentados conferem utilidade e confiança à informação contábil, tornando-a elemento fundamental no processo decisório dos stakeholders. Por outro lado, informações sem os referidos atributos não serão capazes de influenciar o processo decisório, perdendo, consequentemente, sua legitimidade junto aos usuários.

\section{Aspectos Metodológicos}

\subsection{Etapas da pesquisa}

Como estratégia metodológica, utilizou-se de estudos de casos múltiplos por serem considerados mais atraentes do que estudos isolados, bem como por ser um método considerado mais robusto (Yin, 2003). Nas instituições em que a coleta de dados foi realizada presencialmente, tais como a Universidade Federal de Uberlândia (UFU), a Universidade Federal de Ouro Preto (UFOP) e o Instituto Federal do Triângulo Mineiro (IFTM), foram realizadas entrevistas com os gestores do departamento de licitações, com o intuito de complementar as análises documentais.

O protocolo de pesquisa, aprovado previamente em Comitê de Ética e Pesquisa foi estruturado da seguinte forma: (a) data das entrevistas (Setembro/2019 a Janeiro/2020); (b) critério para definição dos respondentes, que seriam os atores que lidam com a execução da etapa de QEF dos órgãos contratantes. 
A duração das entrevistas foi de trinta a cinquenta minutos, conforme o nível de abertura e objetividade do entrevistado. A pesquisa primou pelos atributos de validade e confiabilidade do instrumento, pois se entende que fatores relacionados à tendenciosidade e às falibilidades intrínsecas à natureza humana podem interferir na pesquisa (Mackinnon, 1988). Assim, as entrevistas tiveram como objetivos esclarecer e confirmar as informações dos processos e também permitir a triangulação dos métodos.

As análises foram consolidadas por meio do método Qualitative Comparative Analysis (QCA), que consiste em um método de análise qualitativa que apresenta melhor desempenho quando empregado com estudos de casos que focam na qualidade causal de seus resultados (Schneider \& Rohlfing, 2013). O modelo da QCA adotado para analisar o fenômeno foi a crisp-set (csQCA) que emprega as condições causais que são dicotômicas, utilizando-se de valores que podem ser traduzidos em 0 ou 1 (ausente ou presente). Este modelo foi adotado pelo fato de ser apropriado para estudos com pequeno número de casos, e permite o aprofundamento de suas características causais (Rihoux \& Marx, 2013). A QCA é comumente aplicada em estudos da área Sociológica e da Ciência Política (Rihoux; Marx, 2013), mas vem sendo utilizada em pesquisas na área de contabilidade no Brasil, como é o caso de Lino et al. (2019) e Dias et al. (2020).

Para a análise da QCA, foram executados três passos. Primeiramente, foram realizadas análises documentais, buscando inconsistências nas análises. As inconsistências foram verificadas, comparando-se a ação que deveria ter sido realizada em cada etapa no processo de licitação, como, por exemplo, analisar se as demonstrações contábeis apresentavam inconsistências internas que apontavam para indícios de gerenciamento de resultados, erros ou fraudes. Em seguida, foi elaborado uma tabela de condições causais que organizou as informações consideradas necessárias e que devem estar presentes para que a condição testada na tabela QCA seja validada.

Após esse procedimento, construiu-se a tabela verdade a partir das informações extraídas do segundo passo, utilizando como referência (benchmarking) um processo licitatório do Conselho Federal de Contabilidade (CFC). Este processo teve como objeto a contratação de serviços técnicos especializados, destinados a elaboração e aplicação de prova do Exame de Suficiência do CFC, conforme Pregão Eletrônico № 002/2019. A referida instituição (CFC) utilizou como referência a literatura contábil tanto para a elaboração do edital de licitação no que tange as exigências de QEF quanto na etapa de análise das demonstrações contábeis.

A amostra dos casos compreendeu cinco Instituições Federais de Ensino Superior (IFES) e um Instituto Federal de Educação Ciência e Tecnologia localizado no Estado de Minas Gerais (MG). Destacase que, no Estado de Minas Gerais, há 11 (onze) Universidades Federais e 5 (cinco) Institutos Federais de Educação Ciência e Tecnologia. A Tabela 2 apresenta as instituições analisadas e a caracterização dos casos.

Tabela 2:

Amostra: Instituições Federais, obtenção dos documentos e quantidade de processos analisados

\begin{tabular}{clccc}
\hline Item & \multicolumn{1}{c}{ Instituições } & $\begin{array}{c}\text { Forma de } \\
\text { obtenção }\end{array}$ & $\begin{array}{c}\text { Qte de } \\
\text { processos }\end{array}$ & $\begin{array}{c}\text { Período coleta de } \\
\text { dados }\end{array}$ \\
\hline 1 & Universidade Federal de Lavras (UFLA) & LAl & 4 & Janeiro -2020 \\
2 & Universidade Federal de Minas Gerais (UFMG) & LAl & 1 & Janeiro- 2020 \\
3 & Universidade Federal de Ouro Preto (UFOP) & Presencial & 3 & Outubro - 2019 \\
4 & Universidade Federal de Uberlândia (UFU) & Presencial & 3 & Setembro -2019 \\
5 & Universidade Federal de Viçosa (UFV) & LAl & 2 & Janeiro -2020 \\
6 & Instituto Federal do Triângulo Mineiro (IFTM) & Presencial & 2 & Janeiro -2020 \\
\hline
\end{tabular}

Fonte: Dados da pesquisa.

A cada Instituição de Ensino foram solicitados, no mínimo, três processos licitatórios selecionados de forma aleatória dentre aqueles rescindidos de forma unilateral por motivos de descumprimentos de cláusulas contratuais pelas contratadas. Os documentos dos casos UFU, IFTM e UFOP foram coletados presencialmente, no próprio órgão, mediante autorização dos respectivos gestores. Quanto aos demais, os documentos foram recebidos mediante ofício ou por meio de solicitação via LAl. A análise documental compreendeu quinze processos de seis instituições, conforme exibe a Tabela 3.

Tabela 3:

Modalidade e objeto de cada contrato analisado por Unidade Gestora (UG)

\begin{tabular}{|c|c|c|c|c|c|c|c|c|c|c|c|c|c|c|c|}
\hline \multirow[t]{2}{*}{ ITEM } & \multicolumn{3}{|c|}{ UFU } & \multicolumn{3}{|c|}{ UFOP } & \multicolumn{2}{|c|}{ IFTM } & \multicolumn{4}{|c|}{ UFLA } & \multicolumn{2}{|c|}{ UFV } & \multirow{2}{*}{$\begin{array}{c}\text { UFMG } \\
\mathrm{C} 1 \\
\end{array}$} \\
\hline & $\mathrm{C} 1$ & $\mathrm{C} 2$ & $\mathrm{C} 3$ & $\mathrm{C} 1$ & $\mathrm{C} 2$ & C3 & $\mathrm{C} 1$ & $\mathrm{C} 2$ & $\mathrm{C} 1$ & $\mathrm{C} 2$ & C3 & $\mathrm{C} 4$ & $\mathrm{C} 1$ & $\mathrm{C} 2$ & \\
\hline Modalidade & 1 & 2 & 3 & 1 & 1 & 1 & 1 & 1 & 3 & 3 & 3 & 3 & 1 & 1 & 3 \\
\hline Objeto contratual & 1 & 2 & 2 & 1 & 1 & 1 & 1 & 1 & 2 & 2 & 2 & 2 & 1 & 1 & 2 \\
\hline
\end{tabular}

Notas: (a) Legenda para item de contrato: (C1) Contrato 1; (C2) Contrato 2; (C3) Contrato 3; (C4) Contrato 4;

(b) Legenda para modalidades licitatórias: (1) Pregão Eletrônico; (2) Tomada de Preços; (3) Concorrência;

(c) Legenda para o objeto contratual: (1) Mão de Obra Terceirizada; (2) Construção Civil.

Fonte: Dados da pesquisa. 
Para cada contrato realizou-se o exame de conteúdo das informações da etapa de QEF, confrontando-se as exigências tanto do Edital quanto da legislação com as Características Qualitativas da Informação Contábil, bem como com a literatura contábil, tal como proposto por Martins et al. (2020). Foram analisados os seguintes documentos em cada processo de licitação: edital de licitação, balanço patrimonial e demonstração de resultado das empresas vencedoras do certame, contrato, termo de distrato, justificativas das empresas para a o descumprimento dos contratos e os pareceres da procuradoria em relação aos motivos de rescisão.

\subsection{Apresentação dos Casos}

Cada entidade analisada tem particularidades relacionadas à sua gestão, que envolvem desde questões orçamentárias, gestão de compras e questões relativas à descontinuidade de contratos (Tabela 4). Com exceção da UFOP, não existe nos demais casos investigados profissionais da contabilidade na Comissão de Licitações. Embora a existência de um profissional contábil por si só não possa garantir o processo, pois deve se ater ao princípio da legalidade. Em todos os contratos relacionados à cessão de mão de obra, os motivos da rescisão unilateral foram os mesmos, ou seja, relacionados à falta de cumprimento de obrigações trabalhistas, tais como, atrasos e não pagamento de salários, e a falta de recolhimento de encargos sociais.

Tabela 4:

Caracterização das instituições relacionadas aos contratos analisados

\begin{tabular}{lcccccc}
\hline \multicolumn{1}{c}{ ITEM / IES } & UFU & UFOP & IFTM & UFLA & UFV & UFMG \\
\hline Cidade da Reitoria & Uberlândia & Ouro Preto & Uberaba & Lavras & Viçosa & Belo Horizonte \\
\hline Qte de campi & 7 & 3 & 7 & 1 & 3 & 3 \\
\hline Orçamento anual $^{1}$ & 1.535 .799 & 444.527 & 243.706 & 420.411 & 940.499 & 2.415 .944 \\
\hline Qte de alunos & 31.613 & 13.694 & 10.901 & 12.95 & 18.23 & 51.166 \\
\hline Gestão licitações & Centralizada & Centralizada & Por campus & Centralizada & Centralizada & Centralizada \\
\hline Qte licitações $^{2}$ : & $606 /(-7 \%)$ & $240 /(-40 \%)$ & $89 /(-31 \%)$ & $172 /(-14 \%)$ & $285 /(-15 \%)$ & $2627 /(-13 \%)$ \\
\hline Membros CPL & 9 & 5 & 5 & 5 & 6 & 15 \\
\hline $\begin{array}{l}\text { A QEF é realizada } \\
\text { por Contador }\end{array}$ & Não & Sim & Não & Não & Não & Não
\end{tabular}

Notas: (1) Orçamento anual de 2018 (em R\$ mil); (2) Quantidade de licitações no ano de 2018 com a variação de 2019; (3) Informação extraída por meio de entrevistas.

Legenda: CPL: Comissão Permanente de Licitações; UASG: Unidade de Administração de Serviços Gerais - permite consultas no sistema de compras do governo federal.

Destaca-se que, em um dos contratos rescindidos pela UFOP, foi dada a entrada no seguro do contrato, porém a seguradora alegou que a apólice somente poderia ser acionada após a decisão judicial. A UFOP, nesse caso, se viu obrigada a abrir processo para contratação emergencial, porém os funcionários ainda estavam sem receber seus direitos e aguardando o desfecho da situação. Nos contratos de Construção Civil presentes nos casos da UFU, UFLA e UFMG, os motivos da rescisão foram atrasos e abandono da obra, além de não cumprimento de questões trabalhistas.

\section{Análise da Falta de Legitimação Contábil no Processo Licitatório}

As análises do uso das informações da etapa de QEF foram realizadas em três etapas, quais sejam: 1) Inconsistências nas Demonstrações Contábeis apresentadas pelas empresas; 2) Análise dos Índices Econômico-Financeiros; e 3) Síntese das Análises e aplicação da QCA.

\subsection{Análise das Demonstrações Contábeis}

Em relação à análise, do total de quinze processos, foi verificado que, de $87 \%$ deles (13 contratos), foram apresentados apenas o Balanço Patrimonial (BP) e a Demonstração do Resultado (DR) e, dos outros $13 \%$ (2 dois contratos), foram apresentados apenas o BP, conforme Tabela 5. Nenhum contrato analisado apresentou Notas Explicativas e outras demonstrações contábeis. Apesar do cumprimento parcial da exigência, todas as empresas foram habilitadas para as licitações.

As inconsistências estão em todos os grupos de contas, no entanto são mais evidentes nos grupos circulantes. Cabe chamar a atenção para questões mais relevantes, que poderiam ter sido questionadas, como balanços de períodos incorretos (C1/UFU); balanços com a conta Caixa, representando a totalidade do Ativo (C1/UFU), ou seja, nesse caso não existe evidências contábeis de existência da própria empresa; balanços com a conta Caixa representando quase a totalidade do Ativo (C2/UFV =78,9\%; C2/IFTM = 90\%); lucros muito acima do usual, como $730 \%$ das receitas líquidas (C2/UFU); provisões, representando 63,2\% do Ativo (C2/UFV). Além disso, nenhum dos contratos apresentou notas explicativas e demonstrações completas, sendo que o C2/IFTM e C2/UFLA não apresentaram nem as Demonstrações de Resultado.

A análise horizontal poderia corroborar para a análise de tendências, entretanto a legislação não 
permite que sejam exigidas Demonstrações Contábeis de mais de um exercício financeiro. Diante do exposto, pode-se dizer que a maioria dos Balanços é precária em termos de informação e sem a estrutura mínima de contas. Mesmo assim, todos esses processos foram aprovados nas respectivas licitações.

Tabela 5:

Inconsistências nas Demonstrações Contábeis por contrato analisado

\begin{tabular}{|c|c|c|c|}
\hline IFE & CT & Inconsistências nas DC & Análise Vertical \\
\hline \multirow{3}{*}{ 름 } & C1 & $\begin{array}{l}\text { - Apresentou apenas BP e DR sem NE; BP com saldos na conta } \\
\text { REF sem explicações; BP de exercício incorreto. }\end{array}$ & $\begin{array}{l}\text { - Conta "Clientes" = 49,72\% do AT; } \\
\text { - Conta "Reserva de Impostos a Recuperar" =a 38,5\% } \\
\text { do AT; - LL = a } 22,8 \% \text { das RL. }\end{array}$ \\
\hline & $\mathbf{C 2}$ & $\begin{array}{l}\text { - Apresentou apenas BP e DR sem NE; } \\
\text { - O Ativo apresentou apenas a conta Disponibilidades", como } \\
\text { contrapartida de todo o passivo e PL. }\end{array}$ & $\begin{array}{l}\text { - Conta "Prejuízos Acumulados" = 37,9\% do PT; - O } \\
\text { LL foi negativo em } 730 \% \text { das RL. }\end{array}$ \\
\hline & C3 & $\begin{array}{l}\text { - Apresentou apenas BP e DR sem NE; } \\
\text { - DR com prejuízo. }\end{array}$ & $\begin{array}{l}\text { - Conta "Emp. e Financ. }=51,3 \% \text { do AT; } \\
\text { - Conta "P.A." = } 26 \% \text { do PT. }\end{array}$ \\
\hline \multirow{3}{*}{$\begin{array}{l}0 \\
\text { 임 }\end{array}$} & C1 & - Apresentou apenas BP e DR sem NE. & - Cont. Rec. AC + ANC $=60,34 \%$ do AT. \\
\hline & C2 & - Apresentou apenas BP e DR sem NE. & - Res. de Imp. a Recup. $=38,5 \%$ do PT. \\
\hline & C3 & Apresentou apenas BP e DR sem NE. & $\begin{array}{l}\text { - Clientes + Bancos c/mov. = } 69,9 \% \text { do AT; } \\
\text { - LL totalizou } 47,1 \% \text { do AT; } \\
\text { - Reservas de Capital = 66\% do AT. }\end{array}$ \\
\hline \multirow[b]{2}{*}{$\underline{\underline{E}}$} & C1 & - Apresentou apenas BP e DR sem NE. & - Conta "Caixa" = 90\% do AT; - LL = 43,8\% das RL. \\
\hline & $\mathbf{C 2}$ & $\begin{array}{l}\text { - Apresentou apenas BP. Não apresentou DR e NE; } \\
\text { - Conta "Bancos C/ Mov." foi registrada no AC com saldo } \\
\text { negativo e foi reclassificado para o PC para fins de análise das } \\
\text { DC. }\end{array}$ & - Conta "Adiant. a Sócios" = 30,07\% do AT. \\
\hline \multirow{4}{*}{$\underset{\leftrightarrows}{\leftrightarrows}$} & C1 & $\begin{array}{l}\text { - Apresentou apenas BP e DR. Não apresentou NE; } \\
\text { - Conta com título genérico com saldo elevado: "Clientes } \\
\text { Diversos". } \\
\text { - Parcelamento de diversos Tributos sem explicações. }\end{array}$ & - "Clientes Diversos" = $36,5 \%$ do AT. \\
\hline & $\mathbf{C 2}$ & $\begin{array}{l}\text { - Apresentou apenas BP sem DR e sem NE; } \\
\text { - BP sem estoques, imobilizado e ANC. - "Caixa" com saldo de } \\
\mathrm{R} \$ 505.268,00 \text { enquanto a conta "Fornecedores" tem saldo de } \\
\mathrm{R} \$ 500,00 \text {. }\end{array}$ & $\begin{array}{l}\text { - Não foi apresentada a DR para cálculo dos índices. } \\
\text { - As contas "Clientes" e "Clientes Diversos" equivalem } \\
\text { a 36,5\% do AT. }\end{array}$ \\
\hline & C3 & - Apresentou apenas BP e DR sem NE. & $\begin{array}{l}\text { - Contas "Clientes" e "Clientes Diversos" } \\
\text { =65,6\% do AT; Lucros Acum.=73\% do AT. } \\
\text { - Contas "Clientes" = 44, } 1 \% \text { do AT; }\end{array}$ \\
\hline & C4 & $\begin{array}{l}\text { - Conta “Adiantamento a sócios" com valor elevado e sem } \\
\text { explicações. } \\
\text { - Empresa com valores altos em disponibilidades e ao mesmo } \\
\text { tempo com empréstimos elevados. }\end{array}$ & $\begin{array}{l}\text { - Contas "Adiantamento a Sócios" }=13,9 \% \text { do AT; } \\
\text { - Conta "Empréstimos e Financiamentos" }=37,6 \% \text { do } \\
\text { AT. }\end{array}$ \\
\hline \multirow[b]{2}{*}{ 岂 } & C1 & - Apresentou apenas BP e DR sem NE. & - Conta "Provisões" = 63,2\% do AT. \\
\hline & C2 & - Apresentou apenas BP e DR sem NE. & $\begin{array}{l}\text { - Conta Caixa }=78,9 \% \text { do AT; Devedores } \\
\text { diversos }=44 \% \text { do PT. }\end{array}$ \\
\hline $\mathscr{N}^{0}$ & C & $\begin{array}{l}\text { - Apresentou apenas BP e DR sem NE; } \\
\text { - Disponível elevado c/ aplicação de curto prazo e ainda tomou }\end{array}$ & - A conta "Clientes" = 46,5\% do Ativo Total; \\
\hline
\end{tabular}
Empréstimos para capital de giro $=8,59 \%$ do AT.

Nota: BP (Balanço Patrimonial); DR (Demonstração do Resultado); LL (Lucro Líquido); RL (Receitas Líquidas); AT(Ativo Total); NE (Notas Explicativas); AC (Ativo Circulante); ANC (Ativo Não Circulante); REF (Resultados de exercícios futuros); RSPL: Resultado sobre o Patrimônio Líquido; QEF (Qualificação Econômico-financeira).

Fonte: Elaborado pelos autores com base nos dados da pesquisa

O próximo passo seguido foi a análise dos indicadores econômico-financeiros. Além dos índices exigidos pela legislação (LC, LG e SG), foram calculados os índices: Endividamento, Rentabilidade, Liquidez Imediata (LI) e Índice de Imobilização do Patrimônio Líquido (IPL), conforme apresentado na Tabela 6.

O valor mínimo exigido pela legislação para os indicadores de LC, LG e SG é 1 (um). Destaca-se que o Contrato 2 da UFLA apresentou índices de liquidez fora da realidade setorial ( $L C=1010)$, pois o BP apresentado pela empresa é elementar em termos de informações e estrutura, apresentando apenas duas contas, quais sejam, Caixa e Fornecedores. Além disso, a empresa não apresentou a Demonstração do Resultado. Outros contratos também apresentaram índices de liquidez corrente nada razoáveis (exemplos: $\mathrm{C} 1 / \mathrm{IFTM}=19,9 ; \mathrm{C} 1 / \mathrm{UFLA}=12,17 ; \mathrm{C} 1 / \mathrm{UFU}=7,1)$. Nota-se também que três casos apresentaram índices de rentabilidade negativos (C2/UFU; C3/UFU; C2/UFV), porém esse fato não foi impedimento, conforme determina a legislação. Por outro lado, outros casos chamam a atenção por apresentarem índices de rentabilidade muito altos, haja vista o ROI apresentado (C1/UFLA = 42\%; C4/UFLA = 67\%; C2/UFOP = 99\%; CI/UFU = 206\%). Estas discrepâncias dos índices ratificam aquelas apontadas na Tabela 5.

A defasagem temporal média das demonstrações contábeis corresponde a 10 (dez) meses, havendo licitações que esse período alcançou 16 (dezesseis) meses, como é o caso do Contrato 2 -IFTM. Essa defasagem é permitida legalmente, entretanto prejudicial do ponto de vista da utilidade da informação (Martins et al. 2020). 
Tabela 6:

Indicadores Econômico-Financeiros dos casos analisados

\begin{tabular}{|c|c|c|c|c|c|c|c|c|c|c|c|c|c|}
\hline \multicolumn{2}{|c|}{ ID } & & \multicolumn{4}{|c|}{ Liquidez - Solvência } & \multicolumn{3}{|c|}{ Endividamento } & \multicolumn{4}{|c|}{ Rentabilidade } \\
\hline CASO & $\mathrm{CO}$ & OB & LC & LII & $\mathbf{L G}$ & SG & $\bar{E}$ & CE & IPL & ROI & $\overline{\mathrm{GA}}$ & MOP & RPL \\
\hline \multirow{2}{*}{ IFTM } & 1 & $\mathrm{MO}$ & 19,9 & 19,2 & 19,9 & 21,3 & 0,1 & 1,0 & 0,1 & $31 \%$ & 0,7 & $44 \%$ & $31 \%$ \\
\hline & 2 & $\mathrm{MO}$ & 1,8 & 0,0 & 1,8 & 4,3 & 0,3 & 1,0 & 0,8 & $\mathrm{~s} / \mathrm{dr}$ & $\mathrm{s} / \mathrm{dr}$ & $\mathrm{s} / \mathrm{dr}$ & $\mathrm{s} / \mathrm{dr}$ \\
\hline \multirow{4}{*}{ UFLA } & 1 & $\mathrm{CC}$ & 12,7 & 2,4 & 14,7 & 19,2 & 0,1 & 0,9 & 0,3 & $42 \%$ & 7,0 & $6 \%$ & $21 \%$ \\
\hline & 2 & $\mathrm{CC}$ & 1.010 & 1.011 & 1.011 & 1.011 & 0,0 & 0,5 & 0,0 & - & - & - & - \\
\hline & 3 & $\mathrm{CC}$ & 5,2 & 0,1 & 5,2 & 7,7 & 0,2 & 1,0 & 0,4 & $15 \%$ & 0,9 & $18 \%$ & $8 \%$ \\
\hline & 4 & $\mathrm{CC}$ & 1,9 & 0,3 & 1,9 & 2,3 & 0,8 & 1,0 & 0,3 & $67 \%$ & 3,7 & $18 \%$ & $56 \%$ \\
\hline UFMG & 1 & $\mathrm{CC}$ & 3,0 & 0,2 & 2,3 & 2,4 & 0,7 & 0,8 & 0,4 & $\mathrm{~s} / \mathrm{dr}$ & $\mathrm{s} / \mathrm{dr}$ & $\mathrm{s} / \mathrm{dr}$ & $\mathrm{s} / \mathrm{dr}$ \\
\hline \multirow{3}{*}{ UFOP } & 1 & $\mathrm{MO}$ & 1,3 & 0,3 & 1,1 & 1,3 & 4,0 & 0,8 & 0,2 & $16 \%$ & 5,4 & $4 \%$ & $52 \%$ \\
\hline & 2 & $\mathrm{MO}$ & 6,5 & 3,3 & 6,5 & 8,6 & 0,1 & 1,0 & 0,3 & $99 \%$ & 2,1 & $47 \%$ & $99 \%$ \\
\hline & 3 & $\mathrm{MO}$ & 1,0 & 0,1 & 1,3 & 1,4 & 2,3 & 0,8 & 0,2 & $33 \%$ & 5,2 & $6 \%$ & $24 \%$ \\
\hline \multirow{3}{*}{ UFU } & 1 & $\mathrm{MO}$ & 7,1 & 0,1 & 6,9 & 7,6 & 0,2 & 0,9 & 0,1 & $206 \%$ & 9,0 & $23 \%$ & $104 \%$ \\
\hline & 2 & $\mathrm{CC}$ & 4,1 & 4,1 & 4,1 & - & 0,3 & 1,0 & 0,0 & $-97 \%$ & 0,1 & $-7 \%$ & $-48 \%$ \\
\hline & 3 & $\mathrm{CC}$ & 1,1 & 0,1 & 1,0 & 1,2 & 6,4 & 1,0 & 0,9 & $-89 \%$ & 7,8 & $-504 \%$ & $-219 \%$ \\
\hline \multirow{2}{*}{ UFV } & 1 & $\mathrm{MO}$ & 1,2 & 0,2 & 1,2 & 1,2 & 5,3 & 0,9 & 0,0 & $1 \%$ & 6,1 & $2 \%$ & $7 \%$ \\
\hline & 2 & $\mathrm{MO}$ & 1,2 & 1,1 & 1,3 & 1,3 & 3,2 & 1,0 & 0,2 & $-3 \%$ & 0,9 & $-3 \%$ & $-7 \%$ \\
\hline
\end{tabular}

Nota: CO (Contrato); OB (Objeto do Contrato); LC (Liquidez Corrente); LI (Liquidez Imediata); LG (Liquidez Geral); SG (Solvência Geral); ED (Endividamento); CE (Composição do Endividamento); IPL (Imobilização do Patrimônio Líquido); ROI (Retorno sobre o Investimento); GA (Giro dos Ativos); MOP (Margem Operacional); RSPL (Retorno sobre o Patrimônio Líquido). * Índice não calculado em função da falta de apresentação da Demonstração do Resultado pela empresa.

Fonte: Elaborado pelos autores com base nos resultados da pesquisa

Do ponto de vista da Característica de Compreensibilidade, apenas a UFOP conta com profissional da Contabilidade no Departamento de Licitações, entretanto foi relatado por esta instituição que houve casos em que o Contador tentou ser mais criterioso, e as empresas não concordaram e judicializaram as licitações. Nos demais órgãos, a habilitação econômico-financeira é elaborada pelos agentes das Comissões de Licitações sem que, necessariamente, detenham conhecimentos técnicos específicos de contabilidade (análise das demonstrações contábeis). Já em relação à Característica Capacidade de Verificação, o processo carece de maior transparência, pois as Demonstrações Contábeis não são públicas e não há mecanismos para se confirmar a relação de contratos em que as empresas fazem parte. Salientam-se, inclusive, as dificuldades de acesso para a realização deste estudo.

Em síntese, notou-se que, pelos motivos apresentados, os atributos de valor preditivo e de valor confirmatório da informação contábil não foram atendidos. As DC apresentadas, dificilmente, retratam a realidade econômico-financeira das entidades participantes das respectivas licitações.

\subsection{Análises a partir do Método Qualitative Comparative Analysis (QCA)}

A Tabela 7 sintetiza os resultados da análise documental segundo as características qualitativas da informação contábil. Em cada contrato analisado, atribuiu-se classificação "0" (não atendido) ou "1" (atendido) para cada critério analisado na etapa documental. Por fim, realizou-se a totalização de cada exigência para fins de auxílio na análise de aderência às características qualitativas da informação contábil.

Dentre os critérios associados à característica de Relevância, destacam-se: item "(a) Demonstrações Contábeis exigidas em edital versus apresentadas", em que $100 \%$ dos contratos analisados não apresentaram relatórios além do Balanço Patrimonial e da Demonstração do Resultado; item (b) "Inconsistências apuradas na AV do Balanço Patrimonial", em que 93\% das empresas apresentaram inconsistências; e o item (i) "Índices de Rentabilidade com relevante discrepância setorial", em que 100\% dos contratos analisados não apresentaram congruência com os padrões setoriais, conforme Tabela 7.

Em relação à Representação Fidedigna, observa-se que 100\% das Demonstrações Contábeis não foram auditadas e que $80 \%$ dos processos apresentaram indícios de gerenciamento de resultados. Desse modo, as evidências apontam que as etapas de QEF realizadas nos processos não privilegiaram informações úteis ao processo decisório, pois eram muito frágeis as características qualitativas fundamentais (Relevância e Representação Fidedigna) das informações contábeis utilizadas.

Em relação às Características Qualitativas de Melhoria da Informação Contábil, nota-se a mesma tendência, pois, tratando-se especificamente da Comparabilidade, observou-se que as exigências dos índices econômico-financeiros nos editais não consideraram os parâmetros setoriais e não apresentaram uniformidade, considerando-se os processos do mesmo caso. Outra informação importante relaciona-se à Compreensibilidade, ou seja, em $80 \%$ dos processos analisados, a etapa de QEF não foi realizada por profissional contábil.

Em síntese, observa-se que não há evidências de que o atributo "Adesão", que se refere à aceitação generalizada da norma por seus usuários e que perfaz em condição para se alcançar a legitimidade (Franck, 1990; Bebbington et al, 2012), não está presente na categoria de stakeholders que realizam a QEF. Essa constatação se respalda no fato de que nem as determinações da norma que são consideradas elementares são cumpridas pelos usuários, tal como a verificação de apresentação de todas as demonstrações contábeis e a consistência interna das mesmas. 
Tabela 7:

Critérios analisados segundo as características qualitativas da informação contábil



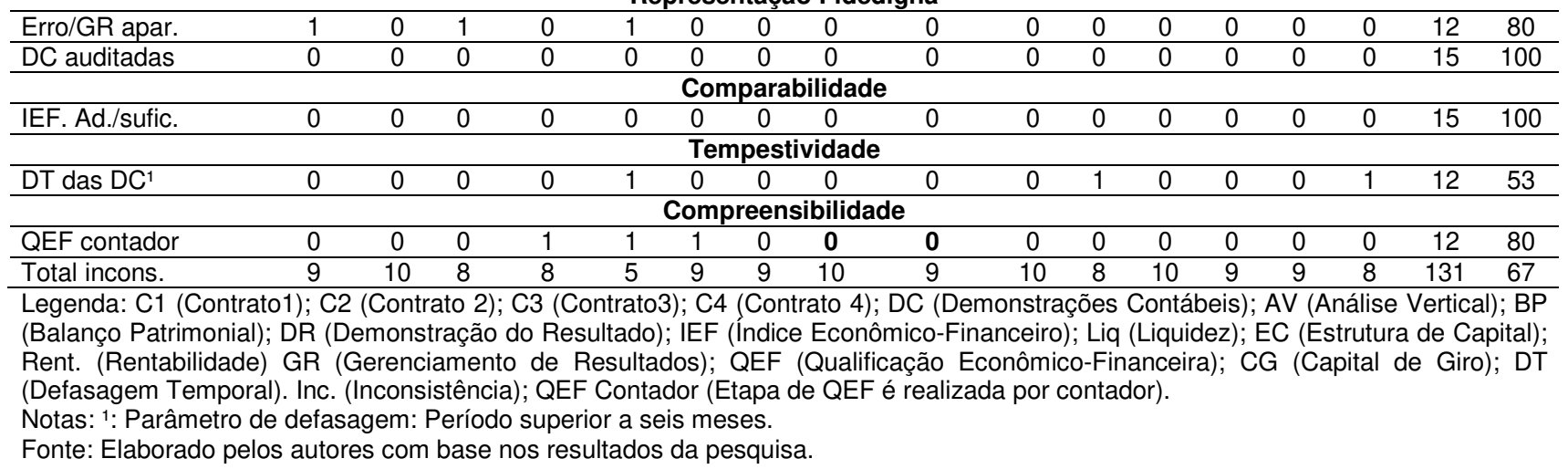

A legitimidade normativa, por meio do atributo de Determinação, fornece explicações para essa situação. A falta de profissional contábil em $80 \%$ dos casos indica que as organizações analisadas não têm visto como necessária a organização do setor de licitações para que essa análise seja feita, mesmo que a avaliação seja de competência do contador por exigência legal.

\subsection{Condições Causais e Resultado da Análise dos Casos}

A partir dos fundamentos da literatura de análise econômico-financeira, de análise de previsão de insolvência, das características qualitativas da informação contábil preconizadas pela Estrutura Conceitual Básica da Contabilidade (CPC 00, 2019) e também das normas brasileiras de contabilidade, avaliando-se quais seriam as condições causais, tanto as necessárias quanto as suficientes para a análise dos casos, chegou-se em cinco condições necessárias, conforme discriminado a seguir:

a) Consistência e abrangência: verifica se todas as demonstrações contábeis foram apresentadas e se as contas contábeis das mesmas apresentam consistência entre os diferentes demonstrativos considerando o tipo e o porte da empresa de acordo com a legislação. Além disso, é necessária a apresentação das demonstrações contábeis de mais de um exercício financeiro para a realização da Análise Horizontal e Vertical.

b) Análise da rentabilidade das empresas em relação ao setor: sem rentabilidade a continuidade da empresa pode estar comprometida. Os estudos de previsão de insolvência revelam que a rentabilidade se constitui em um dos indicadores mais relevantes das previsões (Pereira \& Martins; 2015; Kanitz, 1978). Os índices são mais bem compreendidos quando se estabelecem parâmetros de comparações com o setor.

c) Demonstrações contábeis auditadas: para contratações de valor relevante, as Demonstrações Contábeis devem se sujeitar a auditoria além da verificação de todos os contratos em que a empresa é parte contratada. Há nesse caso, relação com a característica de representação fidedigna em função da verificação de possíveis dissimulações, fraudes e erros. Condição necessária à solução dos casos.

d) Tempestividade: sob a característica da relevância, a informação contábil mais antiga é menos útil. Demonstrações contábeis com defasagem temporal de até dezesseis meses revela perda de utilidade informacional. Portanto, demonstrações contábeis tempestivas perfazem em condição necessária à correta análise econômico-financeira.

e) Compreensibilidade: verificar se as exigências do edital e a realização da análise econômicofinanceira são realizadas por servidor com conhecimentos técnicos necessários. Esta condição é necessária, pois, do contrário, a habilitação econômico-financeira pode não ser realizada adequadamente e muito menos ser útil à avaliação das empresas.

$\mathrm{Na}$ Tabela 8 , as linhas em negrito relativas às condições causais referem-se aos resultados das condições consideradas necessárias, de acordo com a respectiva categoria, para que a informação contábil 
na etapa de QEF seja legítima para avaliar as empresas. Não houve condições causais consideradas suficientes, pois não há subsídios na literatura contábil que apontam para o fato de que apenas a presença isolada de uma condição causal pudesse ser suficiente para se chegar à solução dos casos.

Tabela 8:

Análise das condições causais segundo as características qualitativas da informação

\begin{tabular}{lcccccccccccccccc}
\hline \multicolumn{1}{c}{ Item analisado } & \multicolumn{1}{c}{ UFU } & \multicolumn{4}{c}{ UFOP } & \multicolumn{3}{c}{ IFTM } & \multicolumn{3}{c}{ UFLA } & \multicolumn{3}{c}{ UFV } & UFMG \\
\hline Contratos & C1 & C2 & C3 & C1 & C2 & C3 & C1 & C2 & C1 & C2 & C3 & C4 & C1 & C2 & C1 \\
\hline Modalidade licitatória & PE & TP & CC & PE & PE & PE & PE & PE & CC & CC & CC & CC & PE & PE & CC \\
\hline Objeto da licitação & MO & CC & CC & MO & MO & MO & MO & MO & CC & CC & CC & CC & MO & MO & CC \\
\hline Duração do contrato & 9 & 11 & 6 & 4 & 9 & 3 & 8 & 7 & 17 & 16 & 15 & 24 & 4 & 30 & 17 \\
\hline Motivo da rescisão & OT & A & OT & OT & OT & FL & OT & OT & PO & PO & PO & PO & OT & OT & PO \\
\hline
\end{tabular}

\begin{tabular}{|c|c|c|c|c|c|c|c|c|c|c|c|c|c|c|c|}
\hline \multicolumn{16}{|c|}{ Condições Causais } \\
\hline DC consistentes & 0 & 0 & 0 & 0 & 0 & 0 & 0 & 0 & 0 & 0 & 0 & 0 & 0 & 0 & 0 \\
\hline Todas DC apres. & 0 & 0 & 0 & 0 & 0 & 0 & 0 & 0 & 0 & 0 & 0 & 0 & 0 & 0 & 0 \\
\hline Consistência/abr. & 0 & 0 & 0 & 0 & 0 & 0 & 0 & 0 & 0 & 0 & 0 & 0 & 0 & 0 & $\mathbf{0}$ \\
\hline IEF Rent. Cf Setor. & 0 & 0 & 0 & 0 & 0 & 0 & 0 & 0 & 0 & 0 & 1 & 1 & 1 & 1 & 1 \\
\hline Rentab.cf. setor & 0 & 0 & 0 & 0 & 0 & 0 & 0 & 0 & $\mathbf{0}$ & 0 & 1 & 1 & 1 & 1 & 1 \\
\hline DC auditadas & 0 & 0 & 0 & 0 & 0 & 0 & 0 & 0 & 0 & 0 & 0 & 0 & 0 & 0 & 0 \\
\hline Repres. Fidedigna & 0 & 0 & 0 & 0 & 0 & 0 & 0 & 0 & 0 & 0 & 0 & 0 & 0 & 0 & 0 \\
\hline DC Tempestivas & 0 & 0 & 0 & 0 & 1 & 0 & 0 & 0 & 0 & 0 & 1 & 0 & 0 & 0 & 1 \\
\hline Tempestividade & 0 & 0 & 0 & 0 & 1 & 0 & 0 & 0 & 0 & 0 & 1 & 0 & 0 & 0 & 1 \\
\hline Contador realiza QEF & 0 & 0 & 0 & 1 & 1 & 1 & 0 & 0 & 0 & 0 & 0 & 0 & 0 & 0 & 0 \\
\hline Compreens. & 0 & 0 & 0 & 1 & 1 & 1 & 0 & 0 & 0 & 0 & 0 & 0 & 0 & 0 & 0 \\
\hline
\end{tabular}

Legenda: (a) C1 (Contrato1); C2 (Contrato 2); C3 (Contrato3); C4 (Contrato 4). (b) DC (Demonstrações Contábeis); PE: (Pregão Eletrônico); TP (Tomada de Preços); CC (Concorrência); MO (Mão de obra Terceirizada); CC (Construção Civil); OT (Obrigações trabalhistas); A (Abandono da obra); FL (Falência); PO (Paralisação da Obra); IEF (Índice Econômico-Financeiro); QEF (Qualificação Econômico-Financeira);

Fonte: Elaborado pelos autores com base nos resultados da pesquisa.

A Tabela 8 sintetiza as características causais consideradas necessárias para que a informação contábil seja considerada legítima por seus stakeholders na etapa de QEF. Os itens que incluem a rentabilidade, a auditoria, a tempestividade e a obrigatoriedade de um profissional contábil para realizar a etapa de QEF (Compreensibilidade), são condições necessárias, mas que, atualmente, não são permitidas pela legislação. Caso tivesse ocorrido uma análise mais adequada, são fortes os indícios de que tais empresas não seriam habilitadas.

A QCA (Tabela 9) sintetizou as condições necessárias para a ocorrência dos resultados. Para tanto, foi utilizado como processo padrão (benchmark) um certame licitatório ocorrido no Conselho Federal de Contabilidade (CFC), cujo objeto consistiu na contratação de serviços técnico-especializados para aplicação das provas do Exame de Suficiência. Nesse processo (linha 1 da Tabela 9), todas as condições causais necessárias foram verificadas, obtendo-se como resultado a Legitimidade da Informação Contábil e a reprovação da QEF de várias empresas que não atenderam aos critérios causais.

Nos processos de licitação analisados, chegou-se a seis situações distintas (linhas) envolvendo os contextos causais, mostrando os resultados, em todos eles, que a informação contábil não foi considerada legítima. Destaca-se que a consistência interna e a exigência de todas as DC (Relev1) não foram observadas de forma integral em nenhum dos processos. Nesse caso, havia processos em que constava apenas o Balanço Patrimonial e, mesmo assim, não apresentando estrutura mínima condizente com a lei societária. Desse modo, entende-se que o atributo Adesão à norma por seus usuários, que é indispensável à legitimidade normativa, não se fez presente nas análises dos processos. Um dos motivos seria a falta de concordância ou a falta de entendimento e clareza textual da própria norma (Franck, 1990).

Tabela 9:

Análise da QCA a partir das condições causais

\begin{tabular}{cccccccc}
\hline \multicolumn{7}{c}{ Condições (Contextos causais) } & \multicolumn{2}{c}{ Resultado } & Processos observados \\
\hline Linhas & Rel1 & Rel2 & RFid & Temp. & Comp. & ICont & CFC \\
\hline 1 & 1 & 1 & 1 & 1 & 1 & 1 & UFU-C1; UFU-C2; UFU-C3; IFTM-C1;IFTM-C2;UFLA-C1;UFLA- \\
\hline 2 & 0 & 0 & 0 & 0 & 0 & 0 & C2 \\
\hline 3 & 0 & 0 & 0 & 0 & 1 & 0 & UFOP-C1; UFOP-C3 \\
\hline 4 & 0 & 0 & 0 & 1 & 1 & 0 & UFOP-C2 \\
\hline 5 & 0 & 1 & 0 & 1 & 0 & 0 & UFLA-C3;UFMGC1 \\
\hline 6 & 0 & 1 & 0 & 0 & 0 & 0 & UFLA-C4;UFV-C1; UFV-C2 \\
\hline 7 & 0 & 1 & 0 & 1 & 0 & 0 & UFMG-C1 \\
\hline
\end{tabular}

Legenda: Rel1: Indica se foram verificadas a Consistência interna e a abrangência. Relev2: Indica se a Rentabilidade da empresa foi comparada com a do setor; RFid: Indica se as demonstrações contábeis foram auditadas; Temp.: Indica se a Defasagem Temporal das Demonstrações Contábeis foi observada; Compreens.: Indica se o contador realiza a etapa de QEF; ICont: Indica se a Informação Contábil é relevante e vista como legítima para o processo (Resultado).

Fonte: Elaborado pelos autores com base nos resultados da pesquisa.

A rentabilidade das empresas não consiste em uma exigência da legislação e não foi observada em nenhum processo, porém, em situações como as descritas nas linhas 5, 6 e 7, da Tabela 9, a rentabilidade 
encontrava-se dentro dos parâmetros setoriais. Nesse contexto, empresas foram habilitadas no processo de licitação sem que nenhuma observação fosse feita, mesmo com a existência de prejuízos relevantes e outras inconsistências, como indicação de lucros exorbitantes. Destaca-se ainda que a empresa que venceu a licitação na UFMG não apresentou a demonstração de resultado, contudo, foi habilitada na etapa de QEF do referido processo licitatório. Cabe reforçar aqui a falha da norma, pois embora a etapa seja denominada "Qualificação Econômica e Financeira", a própria norma não permite que se avalie a situação "econômica".

A Compreensibilidade da informação contábil foi associada ao fato de a etapa de QEF ser realizada ou não por um profissional que detenha conhecimento de análise econômico-financeira, visto que apenas os processos que relacionam a UFOP (linhas 3 e 4) atenderam a essa condição causal. Em relação a Tempestividade foi evidenciado que do total de quinze processos analisados, apenas 4 (25\%) não apresentaram demonstrações contábeis defasadas, atendendo às características de relevância e fidedignidade. Destaca-se que no contrato no 02 do caso IFTM, a licitação foi realizada no ano de 2017 e 0 Balanço Patrimonial refere-se ao ano de 2015, pois na data da Licitação, as demonstrações contábeis ainda não haviam sido publicadas, portanto a defasagem temporal corresponde a 16 meses.

Esses achados evidenciam que as informações contábeis utilizadas na etapa de QEF não atenderam aos requisitos necessários que caracterizam informações úteis e relevantes (CPC 00, 2019), mesmo assim os contratos foram estabelecidos. Posteriormente, todos eles foram rescindidos por descumprimento de obrigações trabalhistas, falta de recolhimento de encargos e falta de pagamento de funcionários no caso de serviços terceirizados. No caso das obras de construção civil, os principais motivos se relacionam com falência e atrasos de cronogramas das empresas em funções de questões financeiras. Nota-se que tais contratações poderiam ter sido evitadas se as informações contábeis tivessem sido utilizadas nos processos. Porém, aqueles problemas que decorreriam de falta de qualificação financeira poderiam ser detectados ainda na fase da licitação, o que não vem ocorrendo.

Destaca-se que outros fatores podem causar descontinuidades nos contratos, tais como, erros no projeto, mudanças de legislação ambiental, erros na execução, falta de pagamentos pela Administração Pública e até corrupção. As fragilidades das licitações que este estudo apontou, se constituem em apenas parte de um ambiente de vulnerabilidade da aplicação dos recursos públicos. A realidade das licitações brasileiras é marcada por fatores que envolvem tanto a falta de eficiência quanto à corrupção, conforme apontado pelo Portal da Transparência do governo federal (Transparência, 2020).

Nos três métodos abordados na pesquisa, (análise documental, entrevistas e QCA), observou-se que em geral, a informação contábil não é considerada como instrumento relevante para mitigar as descontinuidades de contratos causados por falta de capacidade econômico-financeira das empresas, inferindo-se a sua baixa legitimidade percebida. Destaca-se que na única instituição (UFOP) que detém profissional contábil na análise da etapa de QEF, o gestor do departamento de licitações afirmou a importância da referida etapa, e também relatou que o servidor que a executa, busca sempre pautar por uma análise criteriosa, mas que as vezes isso não é possível em função de judicialização de processos licitatórios por parte das empresas que não conseguem cumprir com os requisitos determinados. Assim, é notória a necessidade de se alterar a legislação, no que tange a etapa de QEF.

Argumenta-se, então, que esse cenário de baixa utilização da informação contábil nos processos de licitação decorre da baixa utilidade percebida da própria informação, o que decorre da falta de legitimidade do conteúdo da norma. Em outras palavras, como a norma (lei de licitações) exige como regra geral a aplicação das informações da etapa de QEF, mas, como não é validada pelos stakeholders, ela perde importância e não é utilizada. A aprovação da norma ocorreria por meio da realização da análise econômico-financeira de acordo com os atributos presentes nas Características Qualitativas e também nos atributos de Determinação Normativa, que se baseia na clareza e interpretação textual, considerado por Frank (1990) como característica fundamental para se alcançar a legitimidade. Consequentemente, a aceitação pelos stakeholders, com base na coesão da norma com as práticas aceitáveis, impulsionaria a Adesão generalizada pelos usuários.

\section{Considerações Finais}

Este estudo objetivou identificar o nível de legitimação da informação contábil na etapa de QEF dos processos licitatórios de Instituições Federais de Ensino. Observou-se que a informação contábil é apenas uma formalidade solicitada como forma de compliance processual. Isso traz implicações, pois empresas estão sendo selecionadas mesmo sem ter condições de cumprir com o objeto contratual.

O presente estudo corrobora as fragilidades apontadas nos estudos anteriores (Sobreira et al., 2014; Carneiro Júnior et al., 2015) e contribui ao propor uma explicação, que é a baixa legitimidade percebida da informação contábil. Esta pesquisa também corroborou com o estudo de Ribeiro et al. (2020) pois procurou evidências processuais de que a baixa legitimação da informação contábil percebida pelos stakeholders nos processos licitatórios era uma realidade conforme relatado por eles.

Nesse contexto, os resultados encontrados revelam que a informação contábil tem sido vista com baixa legitimidade, devido ao não atendimento das propriedades da norma (Franck, 1990), o que têm prejudicado a avaliação econômica das empresas no processo licitatório. Consequentemente, as 
fragilidades da legislação representam condições causais que não são observadas pelos agentes que realizam a etapa de QEF.

O atributo Determinação não é atendido pela norma, pois a exigência de verificação de outros contratos das empresas, não apresenta os mecanismos necessários para executar essa determinação e, com isso, essa etapa passa a não ser realizada. Além disso, a norma não apresenta coerência ou conexão com outras normas, havendo, por exemplo, falta de alinhamento com as características qualitativas presentes na Estrutura Conceitual da Contabilidade (CPC 00, 2019), bem como com as determinações do Conselho Federal de Contabilidade (CFC) no que tange às prerrogativas profissionais para se realizar a análise econômico-financeira. $O$ atributo Adesão também não está presente no processo de execução da etapa de QEF, pois não se observou concordância com os preceitos da norma, sendo esse fato observado na falta de "obediência" as suas determinações, como, por exemplo, a exigência de todas as demonstrações contábeis que não é atendido pelas empresas, bem como não é cobrado pela administração pública.

É oportuno destacar que nenhuma empresa apresentou as notas explicativas, apresentando duas delas apenas o Balanço Patrimonial. Desse modo, entende-se que elementos da legitimidade normativa, tais como, a determinação e a adesão, podem fornecer explicações causais no que se refere ao objetivo deste estudo, principalmente, em relação aos indícios de que a informação contábil na etapa de QEF não está sendo legitimada por seus usuários como instrumento útil de avaliar a capacidade econômicofinanceira das empresas.

As principais implicações dos resultados encontrados sugerem que a legitimidade normativa seja fundamento para as definições relacionadas às exigências de QEF das empresas que pretendem se relacionar com o setor público. Este estudo demonstrou que os seguintes pontos devem ser observados para se atender à legitimidade da etapa de QEF: a) atribuição de responsabilidade ao profissional (contador ou não) pela emissão de pareceres sobre a situação econômico-financeira das entidades. Tais pareceres fundamentariam as análises, conferindo maior legitimidade à informação contábil; b) divulgação das demonstrações (maior transparência) para que a sociedade possa atuar como "agente fiscalizador" (O'Leary, 2015); c) mudanças nas exigências legais no sentido de contemplar a possibilidade de exigência de informações adicionais como índices de rentabilidade e endividamento, além das demonstrações completas e de, pelo menos, três períodos; d) compartilhamento de informações das empresas entre os entes federativos.

A aplicação efetiva da etapa de QEF poderia mitigar o problema de obras paralisadas no país que se relacionam com os direitos sociais da população, tais como, a educação (escolas), a saúde (hospitais) e a proteção à infância (creches), bem como poderia contribuir para que a prestação de serviços nesses ambientes e em outros necessários ao estado, como o fornecimento de merendas nas escolas, serviços de saúde e segurança, não ficassem paralisados por motivos de abandonos de contratos de empresas aventureiras ou despreparados que atualmente vencem as licitações.

Destaca-se que os seguros de obras, a exemplo do modelo americano (performance bond), não resolveriam os problemas de obras descontinuadas em função dos elevados custos que, no caso do Brasil, são mais acentuados que nos Estados Unidos em função do maior risco estrutural do país, maior insegurança jurídica e maiores riscos trabalhistas. Além disso, com uma obra paralisada, mesmo que o prejuízo financeiro seja atenuado, o atraso temporal pode comprometer as demandas da sociedade, tais como, escolas e hospitais com obras inacabadas. Adicionalmente, no caso de prestação de serviços, o seguro garantia necessita de decisão judicial para ressarcir a administrar pública, e este fato também pode provocar atraso e comprometer o funcionamento das instituições.

Como limitações do trabalho, destaca-se que a análise documental contemplou apenas instituições federais localizadas no Estado de Minas Gerais (MG). Apesar de a legislação que trata das contratações públicas ter eficácia nacional, as realidades dos estados e municípios podem ser distintas em função de particularidades regionais, como escassez de empresas interessadas e aptas a negociar com a administração pública, além da maior rotatividade dos servidores públicos com cargos em comissão em função dos mandatos eletivos. Também se destaca que o problema de descontinuidades de contratos é amplo e pode envolver outras causas. Entretanto, este estudo teve como escopo apenas as descontinuidades causadas por uma falta de avaliação econômico-financeira inadequada ou insuficiente.

Outros elementos podem interferir na relevância percebida e no uso da informação contábil em processos licitatórios. Primeiro, sugere-se analisar se a confiança (Oomsels \& Bouckaert, 2019) entre os stakeholders nas relações de contratações públicas poderia influenciar as análises da informação contábil nesse processo. Segundo, pesquisas recentes têm discutido os problemas e oportunidades enfrentados pela administração pública nas licitações públicas relacionados à entraves tecnológicos (Ashaye \& Irani, 2019). Sugere-se que pesquisas analisem os efeitos da tecnologia no processo de contratação pública, analisando como o processo de digitalização afeta o uso da informação contábil, e em que condições isso ocorre. Terceiro, o processo de licitações como um todo pode ser avaliado sob a ótica do Value for Money (OECD, 2019) em que se pese não só a economicidade, mas a eficiência e a eficácia de todo o ciclo de contratações. Pesquisas podem analisar se a existência desses diferentes direcionadores pode influenciar a forma como a informação contábil é utilizada nos processos. 


\section{Referências}

Aquino, A. C. B., Lino, A. F., Cardoso, R. L., \& Grossi, G. (2020). Legitimating the standard-setter of public sector accounting reforms. Public Money \& Management, 40(7), 499-508.

https://doi.org/10.1080/09540962.2020.1769381

Ashaye, O. R., \& Irani, Z. (2019). The role of stakeholders in the effective use of e-government resources in public services. International Journal of Information Management, 49, 253-270.

https://doi.org/10.1016/j.ijinfomgt.2019.05.016

Ashforth, B. E., \& Gibbs, B. W. (1990). The double-edge of organizational legitimation. Organization Science, 1(2), 177-194. https://doi.org/10.1287/orsc.1.2.177

Atricon (2019). Associação dos Membros dos Tribunais de Contas do Brasil. Documentos. Obras Paralisadas. Recuperado em 20 de setembro, 2019, de http://www.atricon.org.br/wpcontent/uploads/2019/06/Atricon-Obras-Paralisadas.pdf

Bebbington, J., Kirk, E. A., \& Larrinaga, C. (2012). The production of normativity: A comparison of reporting regimes in Spain and the UK. Accounting, Organizations and Society, 37(2), 78-94.

https://doi.org/10.1016/..aos.2012.01.001

Brasil (1988). Constituição da República Federativa do Brasil. Recuperado em 20 de março, 2020, de http://www.planalto.gov.br/ccivil 03/Constituicao/Constituicao.htm

Brasil (1993). Lei no 8.666 de 21 de junho de 1993. Regulamenta o artigo 37, inciso XXI, da Constituição Federal. Recuperado em 02 de junho, 2020, de http://www.planalto.gov.br/ccivil 03/leis//8666cons.htm

Brasil (2017). Instrução Normativa $n^{\circ}$ 2, de 9 de outubro de 2017. Recuperado em 20 de dezembro, 2019, de http://plataformamaisbrasil.gov.br/legislacao/instrucoes-normativas

Broadbent, J., \& Guthrie, J. (2008). Public sector to public services: 20 years of "contextual" accounting research. Accounting, Auditing \& Accountability Journal, 21(2), 129-169.

https://doi.org/10.1108/09513570810854383

Carneiro Júnior, M., de Almeida, L. B., Panhoca, L., \& de Lima, I. A. (2015). Licitações na administração pública: Nova perspectiva para a qualificação econômico-financeira de empresas na contratação de serviços de engenharia e obras civis. Capital Científico, 13(2). https://doi:10.5935/2177-4153.20150011.

Comitê de Pronunciamentos Contábeis (2019). Pronunciamento Técnico CPC 00 (R2) - Estrutura Conceitual para Elaboração e Divulgação de Relatório Contábil-Financeiro. Recuperado em 10 de fevereiro, 2020, de http://static.cpc.aatb.com.br/Documentos/573 CPC00(R2).pdf

Conselho Federal de Contabilidade (2016). Norma Brasileira de Contabilidade, NBC TSP Estrutura Conceitual. Recuperado em 20 de nov, 2019, de https://www1.cfc.org.br/sisweb/SRE/docs/NBCTSPEC.pdf

Deephouse, D. L., \& Suchman, M. (2008). Legitimacy in organizational institutionalism. The Sage Handbook of organizational institutionalism, 49, 77.

Dias, L. N. S., Aquino, A. C. B., da Silva, P. B., \& Santos A. F. (2020). Terceirização de portais de transparência fiscal em prefeituras municipais. Revista de Contabilidade e Organizações, 14, e164383e164383. https://doi.org/10.11606/issn.1982-6486.rco.2020.164383

Du Jardin, P. (2015). Bankruptcy prediction using terminal failure processes. European Journal of Operational Research, 242(1), 286-303. https://doi.org/10.1016/j.ejor.2014.09.059

Franck, T. M., (1990). The power of legitimacy among nations. Oxford University Press on Demand.

Liguori, M., Meyer, R. E., Polzer, T., Rota, S., Seiwald, J., \& Steccolini, I. (2018). Legitimating change in the public sector: the introduction of (rational?) Accounting practices in the United Kingdom, Italy and Austria. Public Management Review, 20(9), 1374-1399. https://doi.org/10.1080/14719037.2017.1383781

Kanitz, S.C. (1978). Como prever falências. São Paulo, Mc Graw-Hill do Brasil, 176 p. 
Lester, P., Borba, J. A., \& Murcia, F. D. R. (2009). Transparência e Governança na Área Pública: Uma Análise da Qualificação Econômica e Financeira das Empresas Licitantes do Estado de Santa Catarina. Revista Eletrônica de Administração, 15(3), 759-782.

Lino, A. F., Carvalho, L. B. D., Aquino, A. C. B. de, \& Azevedo, R. R. de (2019). A falta de trabalho institucional e mudanças organizacionais incompletas em municípios brasileiros. Revista de Administração Pública, 53(2), 375-391. https://doi.org/10.1590/0034-761220170404

Machado, P. L. S. Z. (2006). Contribuição à análise da qualificação econômico-financeira realizada no âmbito das licitações públicas, na modalidade de concorrência, divulgadas pelo governo do Estado de Santa Catarina, no período de janeiro de 2003 até outubro de 2005. Dissertação (Mestrado). http://repositorio.ufsc.br/xmlui/handle/123456789/88923

McKinnon, J. (1988). Reliability and validity in field research: some strategies and tactics. Accounting, Auditing \& Accountability Journal, 1(1), 34-54. https://doi.org/10.1108/EUM0000000004619

Martins, E., Diniz, J. A., \& Miranda, G. J. (2020). Análise avançada das demonstrações contábeis: uma abordagem crítica. São Paulo: Atlas.

Michelin, F.P., Weise, A. D., Medeiros, F.S.B., \& Scheffer, D. (2012). Os Índices de Designação EconômicoFinanceira nos Processos Licitatórios: o caso de uma prefeitura municipal-RS. Ciências Sociais Aplicadas em Revista, 12(23), 185-203.

Milosavljević, M., Dobrota, M., \& Milanović, N. (2019). A New Approach to the Evaluation of Public Procurement Efficiency among European Countries. European Review, 27(2), 246-259. https://doi.org/10.1017/S1062798718000777

OECD. Organisation for Economic Cooperation and Development (2019). Public Procurement. 2019. Recuperado em 15 de dezembro, 2019 de https://www.oecd.org/governance/publicprocurement/. Acesso em: 15 dez.2019.

O'Leary, D. E. (2015). Armchair Auditors: Crowdsourcing Analysis of Government Expenditures. Journal of Emerging Technologies in Accounting, 12(1), 71-91. https://doi.org/10.2308/ieta-51225

Oomsels, P., Callens, M., Vanschoenwinkel, J., \& Bouckaert, G. (2019). Functions and dysfunctions of interorganizational trust and distrust in the public sector. Administration \& Society, 51(4), 516-544. https://doi.org/10.1177/0095399716667973

Parsons, T. (1956). Suggestions for a Sociological Approach to the Theory of Organizations-I. Administrative Science Quarterly, 63-85.

Pereira, V. S., \& Martins, V. F. (2015). Estudos de previsão de falências-uma revisão das publicações internacionais e brasileiras de 1930 a 2015. Revista Contemporânea de Contabilidade, 12(26), 163-196. http://dx.doi.org/10.5007/2175-8069.2015v12n26p163

Ragin, Charles (1987). The Comparative Method: Moving Beyond Qualitative and Quantitative Strategies. Berkeley: University of California Press.

Ribeiro, R. B., Miranda, G. J., \& de Azevedo, R. R. (2021). A baixa legitimação da qualificação econômicofinanceira (QEF) percebida pelos stakeholders nas licitações públicas. Advances in Scientific and Applied Accounting, 1(1), 185-205. https://doi.org/10.14392/asaa.2020130310

Rihoux, B., \& Marx, A. (2013). QCA, 25 years after "The comparative method" mapping, challenges, and innovations-Mini-Symposium. Political Research Quarterly, 66(1), 167-235.

https://doi.org/10.1177/1065912912468269

Rodrigues, B B. C. O., Miranda, , G. J., Lourenço, K. S. (2017). Critérios Relativos à Liquidez Exigidos em Editais de Licitação no Brasil. Anais do Congresso USP de Contabilidade e Controladoria, 17, São Paulo.

Romzek, B. S., \& Johnston, J. M. (2002). Contract implementation and management effectiveness: A preliminary model. Journal of Public Administration Research and Theory, 12(3), 423-453. 
Schneider, C. Q., \& Rohlfing, I. (2013). Combining QCA and process tracing in set-theoretic multi-method research. Sociological Methods \& Research, 42(4), 559-597.

Salancik, G. R., \& Pfeffer, J. (1978). The external control of organizations: A resource dependence perspective (pp. 167-199). New York: Harper \& Row.

Schneider, Carsten Q., \& Wagemann, Claudius (2012). Set-theoretic methods for the social sciences: A guide to qualitative comparative analysis. Cambridge University Press.

Sobreira, A. E., Nascimento, J. C. H. B., da Silva Reis, J., \& de Sousa, W. D. (2014). Avaliação econômicofinanceira por índices contábeis em processos licitatórios: aplicação de Modelo de Análise Discriminante. Revista Brasileira de Contabilidade, (209), 32-43.

TCU (2019). Tribunal de Contas da União Fiscalização de obras. Fiscoobras 2019. Recuperado em 20 de dezembro, 2019, de https://portal.tcu.gov.br/imprensa/noticias/fiscobras-2019-tribunal-apresenta-resultadode-fiscalizacao-em-77-obras-publicas.htm

Transparência Brasil (2020). Portal da Transparência. Ministério da Transparência. Recuperado em 20 de janeiro, 2020, de https://www.transparencia.gov.br

Yin, R. K. (2003). Case study research: design and methods. Thousand Oaks, CA: Sage.

\section{NOTAS}

\section{AGRADECIMENTOS}

Os autores agradecem ao Conselho Nacional de Desenvolvimento Científico e Tecnológico (CNPQ) o apoio à realização desta pesquisa.

\section{CONTRIBUIÇÃO DE AUTORIA}

Concepção e elaboração do manuscrito: R.B. Ribeiro, G.J. Miranda, R. R. de Azevedo

Coleta de dados: R.B. Ribeiro, R. R. de Azevedo

Análise de dados: R.B. Ribeiro, G.J. Miranda, R. R. de Azevedo

Discussão dos resultados: R.B. Ribeiro, G.J. Miranda, R. R. de Azevedo

Revisão e aprovação: R.B. Ribeiro, G.J. Miranda, R. R. de Azevedo

\section{CONJUNTO DE DADOS DE PESQUISA}

Todo o conjunto de dados que dá suporte aos resultados deste estudo foi publicado no artigo e na seção "Materiais suplementares".

\section{FINANCIAMENTO}

Pesquisa financiada pelo Conselho Nacional de Desenvolvimento Científico e Tecnológico (CNPQ) por meio do custeamento dos seguintes itens: diárias, passagens e tradução para a língua inglesa. O título do projeto registrado no CNPQ: "Características Qualitativas das Informações Contábeis nas Contratações Públicas no Brasil", Processo: 429801/2018-1, edital-chamada MCTIC/CNPq № 28/2018.

\section{CONSENTIMENTO DE USO DE IMAGEM}

Não se aplica.

\section{APROVAÇÃO DE COMITÊ DE ÉTICA EM PESQUISA}

A pesquisa foi submetida e aprovada pelo Comitê de Ética da Universidade Federal de Uberlândia, conforme Parecer № 4.026.299 de treze de Maio de 2020. Registrado na Plataforma Brasil sob o № 18049219.4.0000.5152.

\section{CONFLITO DE INTERESSES}

Não se aplica.

\section{LICENÇA DE USO}

Os Direitos Autorais para artigos publicados neste periódico são do autor, com direitos de primeira publicação para a Revista. Em virtude de aparecerem nesta Revista de acesso público, os artigos são de uso gratuito, com atribuições próprias, em aplicações educacionais, de exercício profissional e para gestão pública. A Revista adotou a licença Creative Commons Atribuição 4.0 Internacional - CC BY NC ND. Esta licença permite acessar, baixar (download), copiar, imprimir, compartilhar, reutilizar e distribuir os artigos 
desde que com a citação da fonte, atribuindo os devidos créditos de autoria. Nesses casos, nenhuma permissão é necessária por parte dos autores ou dos editores. Autores têm autorização para assumir contratos adicionais separadamente, para distribuição não-exclusiva da versão do trabalho publicada nesta revista (ex.: publicar em repositório institucional ou um capítulo de livro).

\section{PUBLISHER}

Universidade Federal de Santa Catarina. Curso de Ciências Contábeis e Programa de Pós-graduação em Contabilidade. Publicação no Portal de Periódicos UFSC. As ideias expressadas neste artigo são de responsabilidade de seus autores, não representando, necessariamente, a opinião dos editores ou da universidade.

\section{EDITORES}

Carlos Eduardo Facin Lavarda e Suliani Rover

\section{HISTÓRICO}

Recebido em: 19/07/2020 - Revisado por pares em: 09/02/2021 - Reformulado em: 08/03/2021 Recomendado para publicação em: 07/05/2021 - Publicado em: 30/06/2021 